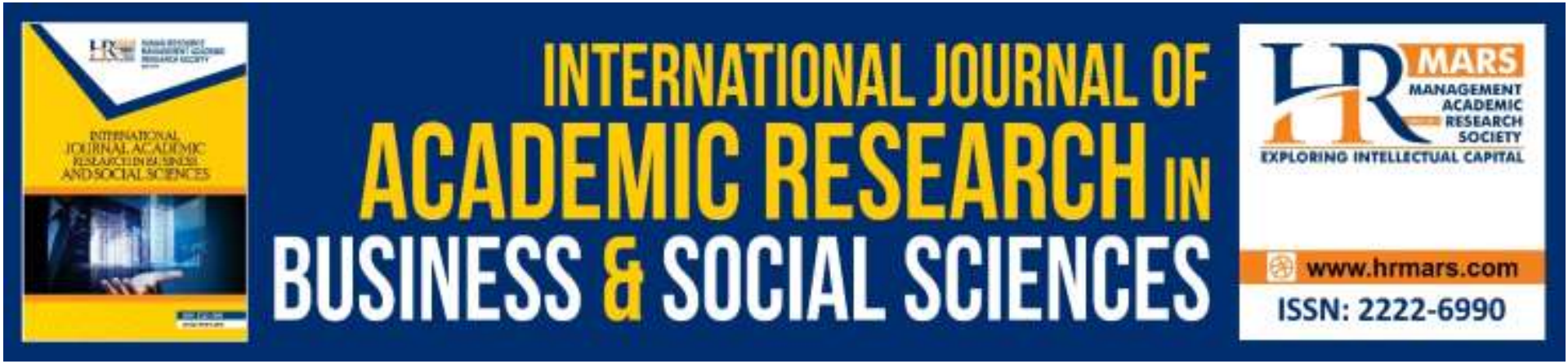

\title{
Identifying The Determinants for Developing of Smart City Initiatives in Delivering Convenience and Safety to Local Community
}

Tan Tze Horng, Mohd Ibrani Shahrimin Bin Adam Assim, Chong Kim Mee, Lai Hon Kuan

To Link this Article: http://dx.doi.org/10.6007/IJARBSS/v11-i17/11404 DOI:10.6007/IJARBSS/v11-i17/11404

Received: 09 August 2021, Revised: 29 August 2021, Acepted: 22 September 2021

Published Online: 11 October 2021

In-Text Citation: (Horng et al., 2021)

To Cite this Article: Horng, T. T., Assim, M. I. S. B. A., Mee, C. K., \& Kuan, L. H. (2021). Identifying The Determinants for Developing of Smart City Initiatives in Delivering Convenience and Safety to Local Community. International Journal of Academic Research in Business and Social Sciences, 11(17), 229-236.

Copyright: (C) 2021 The Author(s)

Published by Human Resource Management Academic Research Society (www.hrmars.com) This article is published under the Creative Commons Attribution (CC BY 4.0) license. Anyone may reproduce, distribute, translate and create derivative works of this article (for both commercial and non-commercial purposes), subject to full attribution to the original publication and authors. The full terms of this license may be seen at: http://creativecommons.org/licences/by/4.0/legalcode

Special Issue Title: Empowering Community and Beyond, iRandau, 2021, Pg. 229 - 236

Full Terms \& Conditions of access and use can be found at http://hrmars.com/index.php/pages/detail/publication-ethics 


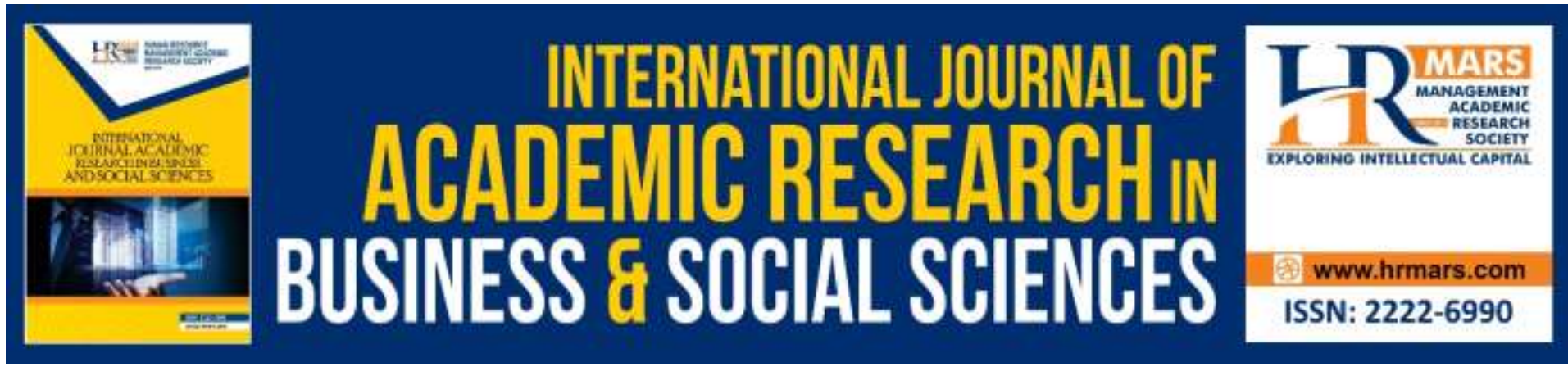

\title{
Identifying The Determinants for Developing of Smart City Initiatives in Delivering Convenience and Safety to Local Community
}

\author{
Tan Tze Horng ${ }^{1}$, Mohd Ibrani Shahrimin Bin Adam Assim¹, \\ Chong Kim $\mathrm{Mee}^{2}$, Lai Hon Kuan ${ }^{1}$ \\ ${ }^{1}$ Universiti Putra Malaysia Kampus Bintulu, Sarawak, ${ }^{2}$ Riam Institute of Technology, Miri, \\ Sarawak \\ Email: tantzehorng@gmail.com
}

\begin{abstract}
Cities in Malaysia are facing rapid urbanisation in the last decades and common issues faced by these cities include traffic congestion, environment pollution, security and deterioration of natural resources. Smart cities, in global context, are introduces as solutions to the urban issues. For Malaysia, smart cities are a new approach in urban management and development to make the cities more sustainable and liveable. This study analyses many of these challenges, in developing the smart city initiatives in the local context, offering a valuable insight of the relevant key literature, and a foundation for the development of smart city initiatives blueprint. The objectives of the study are to ascertain the determinants for developing of smart city initiatives and identify the level of importance for these initiatives from the local community perspectives. The study includes 20 items in the smart city initiatives such as public safety, public convenience, residents' participation, communication and information, urban mobility (transportation), wastewater treatment, smart payment and finance, garbage collection services, neighbourhood maintenance / cleaning services, CCTVs monitoring system (traffic monitoring) and so forth. This is an online survey and a total of 533 valid responses are received from the questionnaires which are presented in three languages and were analysed using IBM Statistical Package for the Social Sciences (SPSS). The data are first analysed for reliability and validity and the determinants' mean and variance are calculated for significant comparison purposes. The findings clearly indicate that the most important determinant in Miri's Smart City initiatives is the garbage collection services which reflect the local community's concerns for the quality of life and the public community services in the neighbourhood.
\end{abstract}

Keywords: Smart Cities, Local Community, Sustainability, Convenience, Safety

\section{Introduction}

According to the United Nations, $68 \%$ of the world population will be living in urban areas by 2050, with almost 90 percent growth happening in Asia and Africa (United Nations, 2018a). As depicted in Figure 1, Malaysia urbanisation inevitably will reach approximately 90 percent 
growth by 2050 (United Nations, 2018b), for that, according to Malaysia Smart City Framework (MSCF, 2019), smart city is the new approach in urban management and development to make cities in Malaysia more liveable and sustainable. The smart city initiatives in Malaysia have been embedded in the Eleventh Malaysia Plan (11MP), the National Physical Plan 3 (NPP3) and the National Urbanisation Policy 2 (NUP2). Such emphasise highlights the role of smart cities development in coping with Malaysia's urbanisation issues and its impact on sustainability. However, a review carried out by Lim, Abdul Malek, Hussain and Tahir (2020) on the MSCF revealed that the framework focuses on the technological aspects and these initiatives are lacking citizenship involvement and engagement in building a united society. In other words, the smart city initiatives should not only stress on the society's hardware development but also the software namely the human factors to ensure its success and continuity.

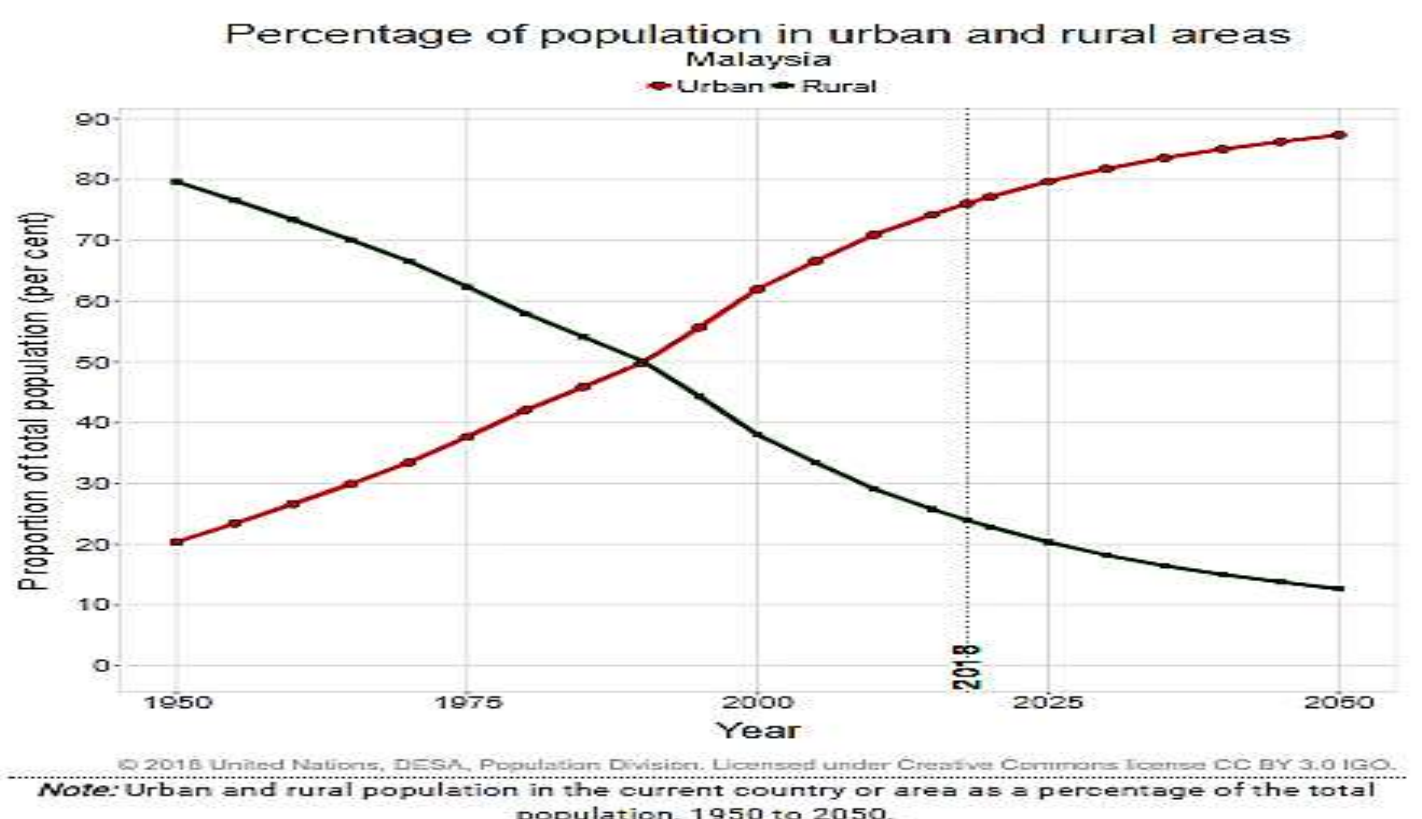

Figure 1: Malaysia Population in Urban and Ural Areas (1950-2050)

Source: United Nations (2018b)

Therefore, this study intends to identify and understand the stakeholders' involvement in the smart city development and implementation as this is also one of the gaps identified by Patrão, Moura and De Almeida (2020), in their study. This study focuses on the level of awareness and perceptions of the local community towards the smart city initiatives through the identification of most relevant determinants in shaping a viable smart city model. To begin with, based on a literature study by Patrão et al (2020), different expressions can be found in defining "smart city', for the purpose of this study the term "smart city" is adopted as it is the most widespread and acceptable term among the citizens, media and other stakeholders (Höjer and Wangel, 2015). The Smart Cities Council defines smart cities as communities that use information and communication technology to enhance liveability, workability, and sustainability (ICMA, 2016). The findings of this survey provide insight into the determinants of smart city initiatives in Malaysia from the perspectives of local community, which correspond to the definition of the smart cities' definition mentioned. Porru et al (2020) survey on the smart mobility and public transport conclude that the future's mobility needs should be leveraging on the Internet of Things (IOT) technologies to ensure its sustainability in the smart cities. A such, it is vital that the inclusion of online networks for 
public convenience which include the urban transportation, information and communications and others in the smart cities initiatives to better serve its local community should be capitalised on the potential of the loT. Moreover, Patrão et al (2020) note that the smart city initiatives intend to address urbanisation challenges through new ways and solve multidisciplinary problems in city. As such, it is imperative to identify and assess these initiatives with appreciate instruments. Such instruments could vary depending on the contexts under study and thus it is imperative to identify the smart cities initiatives related to local community as "citizen-centric" in deciding the most relevant determinants in a particular setting (Malek, Lim and Yigitcanlar, 2021). For instance, in the case of United States, based on the survey done by ICMA (2016) through 3,423 local governments, it is found that the top 5 priorities in the smart city initiatives are technologies in public safety, customer service/pubic engagement, water and wastewater, telecommunications and transportation. Other than that, online social networks such as Instagram and Facebook provide valuable information which can be used by governments, policymakers and other stakeholders (Ismagilova et al., 2020). Their study postulates the need for stakeholders of smart city to enhance the privacy protection on the social networks taking into considerations of individual behaviour in social networks. A remarkable insight from ICMA finding is smart city initiatives would be managed through a combination of systems or support from external consultants and systems operated and developed internally (ICMA, 2016). Such notion is as well reflected in Miri's Smart City Command Centre where the centre handles public communications through smart city mobile app and it is a jointly effort of the systems operator and the city council. Smart payments and finance are ranked as the most reported5 smart city initiatives in the United States (ICMA, 2016). In Malaysia, cashless payment is widely used with important consideration given to performance expectancy and facilitating condition (Rahman, Ismail and Bahri, 2021). As such with the introduction of smart city initiatives in Miri, the inclusion of smart payment and finance in the framework can be self-explanatory and highly relevant. Furthermore, as Sinha, Gupta, Singh and Jamshed (2020) reveal in their study of trash management in India, garbage collection and management must be handled in the early stage of the smart city's development as urban community produce a magnitude ton of garbage every day. In such case, garbage trucks equipped with GPS sensors enable the garbage collection services to be monitored and managed within the communities (Kasliwal and Suryawanshi, 2016).

\section{Method}

This survey was conducted via online survey form sent to the local community in the Miri City in Sarawak, Malaysia. The objectives of the study are to ascertain the determinants for developing of smart city initiatives and identify the level of importance for these initiatives from the local community perspectives. From a holistic and multidisciplinary secondary data research and reviews of studies on smart cities carried out in different nations, 20 determinants of smart city initiatives are explored and included in this study. These determinants consist of public safety, public convenience, ease of use, money saving, time saving, residents participation, smart city command centre, disaster / flood warning, communication and information, urban mobility (transportation), wastewater treatment, smart payment and finance, free wi-fi zones, garbage collection services, neighbourhood maintenance / cleaning services, promotion of tourism, social networks of the city council, administrative procedures online, CCTVs monitoring system (traffic monitoring) and ease of conducting business. These determinants are measured in the scale of seven, from 1 as Least Important to 7 as Very Important. All the respondents must reside in Miri City for more than 
5 years and only those respondents who are aged 18 and above are allowed to complete the questionnaire. According to Miaoulis and Michenner (1976) three criteria for determining appropriate sample size are the level of precision, confidence or risk level, and the degree of variability in the attributes being studied. In this study the level of precision or sampling error is estimated at \pm 5 percent, and such value is the same as political campaign polls statistics which are carried out at large scale (Israel, 1992). In addition, the central limit theorem posits that the average value of the attributes obtained by those samples is equal to the true population value (Fischer, 2011), that said, in a normal distribution, approximately 95 percent of the sample values are within two standard deviations of the true population, thus this study opts for confidence level of 95 percent which implies 95 out of 100 samples will contributes to the true population value within \pm 5 percent of sampling error. The degree of variability in this study is reflected in the heterogenic population background of the population under study, where indigenous people form the largest ethnic group in the city (65 percent) comprises Iban, Malay, Melanau, Bidayuh and other indigenous tribes. This is followed by Chinese (34.1 percent), Indians (0.5 percent) and others (Department of Statistics Malaysia, 2010). Such high degree of variability in the attributes requires larger sample size to ensure the appropriateness of the sample size selected (Israel, 1992). Moreover, Johnson and Shoulders (2019) suggested increasing sample size based on the anticipated response rate to achieve the number of responses required, as such, the sample size for this study is determined at 550 valid responses, and with an estimated response rate of $50 \%$, the targeted respondents will be 1,100. Using the above criteria and statistical considerations, Krejcie and Morgan (1970) formula shows the sample size of 384 based on 5 percent of confidence interval with a population size of 250,000 with 95 percent of confidence level. As the population under study is estimated as lower than 234,541 (Department of Statistics Malaysia, 2010) exclusive of citizens below 18 years old, and non-residents, such sample size is deemed to be suitably representative of the true population. In support of the sample size choice, Cochran (1977) recommended calculating required sample size for each item and deciding on the largest calculated sample size. With reference to Cohen's $(1988, p .54)$ power tables, to equal the Type I error with Type II error risk, the sample size of 542 is set as the baseline with the desire power of 0.95 and effect size of .80(.20). Effect size of .20 is selected with the idea that Type I errors are of the order of four times as serious as Type II errors with the order .20/.05, the .80 desired power convention is preferred (Cohen, 1988).

The survey of the local community is conducted through online survey form and a total of 533 sets of valid responses are received from the questionnaires which were presented in three languages, namely Chinese, English, and Malay language. The determinants of for developing of smart city initiatives were identified and the ranking of the dimensions' importance are analysed and concluded in this study. This study concludes with local community's perceptions of a smart city and provides recommendations for future study on smart cities. This study uses quantitative survey of the self-administrated questionnaire and the findings are analysed using IBM Statistical Package for the Social Sciences (SPSS). The data are first analysed for reliability and validity and the determinants' mean and variance are calculated for significant comparison purposes.

\section{Results}

Based on the data collected, the reliability of the data is accepted with the Cronbach's Alpha of .958 showing a high degree of reliability among the data (Table 1). The validity of the data 
is shown in Table 2 with Kaiser-Meyer-Olkin test of .951. This implies that the sampling is adequate for the factor analysis.

Table 1: Data Reliability Test

\begin{tabular}{|l|l|l|}
\hline Reliability Statistics & $\begin{array}{l}\text { Cronbach's Alpha Based on } \\
\text { Standardized Items }\end{array}$ & N of Items \\
\hline .958 & .959 & 20 \\
\hline
\end{tabular}

Table 2: Data Validity Test

\begin{tabular}{|l|l|l|}
\hline \multicolumn{2}{|l|}{ KMO and Bartlett's Test } \\
\hline Kaiser-Meyer-Olkin Measure of Sampling Adequacy. & .951 \\
\hline Bartlett's Test of Sphericity & Approx. Chi-Square & 8378.746 \\
\cline { 2 - 3 } & df & 190 \\
\cline { 2 - 3 } & Sig. & .000 \\
\hline
\end{tabular}

The subsequent analysis involves the calculation of mean and variance for data of the 20 determinants collected. As depicted in Table $\mathbf{3 a}$ and $\mathbf{3 b}$, the statistics show that Garbage Collection Services (GCS) has the highest mean value at 6.5009 and Residents Participation (RP) being the lowest at 6.0525. There are 5 determinants with a mean of 6.4 above and under 6.5, these include Public Safety (PS, 6.4296), Time Saving (TSV, 6.4221), Disaster/Flood Warning (DFW, 6.4034), Communications and Information (C\&I, 6.4672), and Neighbourhood Maintenance / Cleaning Services (NMCS, 6.4409). There are 9 determinants with lower mean from 6.3 above and under 6.4, these are Public Convenience (PC, 6.3696), Ease of Use (EoU, 6.3508), Urban Mobility (Transportation) (UMT, 6.3996), Wastewater Management (WWT, 6.3621), Smart Payment and Finance (SP\&F, 6.3077), Free Wi-Fi Zone (FWFZ,6.3283), Administrative Procedures Online (APO, 6.3171), CCTVs monitoring system (CCTV, 6.3790), and Ease of Conducting Business (ECB, 6.3152). The Social Networks of the City Council (SNC) and Money Saving determinants score 6.2477 and 6.2139 respectively. These are followed by Promotion of Tourism (PoT, 6.1951) and Smart City Council Command Centre (SCCC, 6.0788).

Table 3a: Mean and Variance of the Smart City Initiatives Determinants

\begin{tabular}{|l|l|l|l|l|l|l|l|l|l|l|}
\hline Items & PS & PC & EoU & MSV & TSV & RP & SCCC & DFW & C\&I & UMT \\
\hline Mean & 6.4296 & 6.3696 & 6.3508 & 6.2139 & 6.4221 & 6.0525 & 6.0788 & 6.4034 & 6.4672 & 6.3996 \\
\hline Variance & .892 & .854 & .905 & 1.251 & .808 & 1.384 & 1.219 & 1.079 & .855 & .857 \\
\hline
\end{tabular}

Table 3b: Mean and Variance of the Smart City Initiatives Determinants (continued)

\begin{tabular}{|l|l|l|l|l|l|l|l|l|l|l|}
\hline Items & WWT & SP\&F & FWFZ & GCS & $\begin{array}{l}\text { NMC } \\
\text { S }\end{array}$ & PoT & SNC & APO & CCTV & ECB \\
\hline Mean & $\begin{array}{l}6.362 \\
1\end{array}$ & $\begin{array}{l}6.307 \\
7\end{array}$ & $\begin{array}{l}6.328 \\
3\end{array}$ & $\begin{array}{l}6.500 \\
9\end{array}$ & $\begin{array}{l}6.440 \\
9\end{array}$ & $\begin{array}{l}6.195 \\
1\end{array}$ & $\begin{array}{l}6.247 \\
7\end{array}$ & $\begin{array}{l}6.317 \\
1\end{array}$ & $\begin{array}{l}6.379 \\
0\end{array}$ & $\begin{array}{l}6.315 \\
2\end{array}$ \\
\hline $\begin{array}{l}\text { Varianc } \\
\text { e }\end{array}$ & 1.036 & .965 & 1.232 & .837 & .848 & 1.146 & .995 & .901 & .946 & .946 \\
\hline
\end{tabular}

\section{Discussion}

Based on the findings, the most important determinants in Miri's Smart City initiatives are the garbage collection services, which reflect the local community's concerns for the quality of 
life and the public community services in the neighbourhood. Such perceptions are highly relatable to the community as the priority of a liveable city will be its hygienic and healthy environments. Other significant determinants in the smart city initiatives are as well related to the local community personal and environment well-being such as public safety, time saving, disaster/flood warning neighbourhood maintenance / cleaning services such as grass cuttings, lamp post maintenance and so on, and communications and information. Such findings indicate the local community are prioritising the smart city initiatives on the determinants that have profound impact on their neighbourhood safety and sustainability. Other determinants that are related to third party or needed occasionally include public convenience, ease of use, urban mobility (transportation), wastewater management, smart payment and finance, free Wi-Fi zone, administrative procedures online, CCTVs monitoring system and ease of conducting business. It is apparent such determinants are considered as peripheral and they are not playing significant roles in the local community's lives. Such smart city initiatives are regarded as fundamental public amenities and their existence and importance are not realised until situation requires them. Lastly the promotion of tourism in the smart city and ease of doing business are not fully appreciated by the local community as they are not fully aware of the mechanism involved in the smart city initiatives that have the impact on these two determinants. The unwillingness of local community to be involved or participate in the smart city initiatives might be due to insufficient knowledge on the benefits of embracing the smart city endeavours and therefore, leads to low involvement in the smart city initiatives.

\section{Conclusions}

This study provides a snippet of the local community's awareness and perceptions on the smart city initiatives in terms of their roles and importance. However, as the data collected are merely quantitative, it is recommended to conduct in-depth qualitative research to elicit opinions, views, and attitudes from the local community towards the implementation and development of smart city initiatives. Such data is valuable in exploring new dimensions in identifying new determinants of the importance of the smart city initiatives for future study. This study is limited to local community in the Miri City where the demographic factors may influence the outcomes of the study, as such comparative studies are needed in different context to enhance the generalisation of the determinants.

\section{Acknowledgement}

This study is supported by Miri City Council and Sarawak Information System Sdn. Bhd. (SAINS).

\section{References}

Cochran, W. G. (1977). Sampling techniques (3rd ed.). New York City, NY: John Wiley \& Sons. Cohen, J. (1988). Statistical power analysis for the behavioral sciences (2nd ed.). Mahwah, NJ: Höjer, M., \& Wangel, J. (2015). Smart sustainable cities: Definition and Challenges. In ICT Innovations for Sustainability. Springer International Publishing.

ICMA. (2016). Smart Sustainable Cities: Definition and Challenges. Available from: https://www.researchgate.net/publication/310403759_Smart_Sustainable_Cities_Def inition_and_Challenges [Accessed on 24 May 2021]. 
Ismagilova, E., Hughes, L., Rana, N. P., \& Dwivedi, Y. K. (2020). Security, privacy and risks within smart cities: Literature review and development of a smart city interaction framework. Information Systems Frontiers. https://doi.org/10.1007/s10796-020-10044-1

Israel, G. D. (1992). Determining sample size. University of Florida Cooperative Extension Service, Institute of Food and Agriculture Sciences, EDIS, Florida.

Johnson, D. M., \& Shoulders, C. W. (2019). Beyond magic words and symbols: Rethinking common practices in quantitative research. Journal of Agricultural Education, 60(3), 291-303 https://doi.org/10.5032/jae.2019.03291

Kasliwal, M. H., \& Suryawanshi, S.B. (2016). A Novel approach to garbage management using internet of things for smart cities. Journal of Current Trends in Engineering \& Research, 2, pp. 348-53.

Krejcie, R. V., \& Morgan, D. W. (1970). Determining sample size for research activities. Educational and Psychological Measurement, 30, pp. 607-610. https://doi.org/10.1177/001316447003000308

Lim, S. B., Abdul Malek, J., Hussain, M. Y., \& Tahir, Z. (2020). Malaysia smart city framework: A trusted framework for shaping smart Malaysian citizenship? In Handbook of Smart Cities. Springer: Switzerland.

Malaysia Smart City Framework, MSCF. (2019). Ministry of Housing and Local Government. https://www.kpkt.gov.my/resources/index/user_1/GALERI/PDF_PENERBITAN/FRAME WORK/FRAMEWORK_SMART_CITY_FINAL_REPORT_190328.pdf [Accessed on 24 May 2021]

Malek, J. A., Lim, S. B., \& Yigitcanlar, T. (2021). Social Inclusion Indicators for Building CitizenCentric Smart Cities: A Systematic Literature Review. Sustainability 2021, 13, 376. https://doi.org/10.3390/su13010376

Miaoulis, G., \& Michener, R. D. (1976). An Introduction to Sampling. Dubuque, lowa:Kendall/Hunt Publishing Company.

Miri Population. (2010), Department of Statistics Malaysia, https://web.archive.org/web/20150205090002/http://www.statistics.gov.my/portal/ download_Population/files/population/03ringkasan_kawasan_PBT_Jadual1.pdf [Accessed 23 May 2021]

Patrão, C., Moura, P., \& De Almeida, A. T. (2020). Review of smart city assessment tools. Smart Cities 2020. 3, pp.1117-1132.

Porru, S., Misso, F. E., Pani, F. E., \& Repetto, C. (2020). Smart monility and public transport: Opportunities and challenges in rural and urban areas. Journal of Traffic and Transportation, 7(1), pp. 88-97.

Rahman, M., Ismail, I., \& Bahri, S. (2020). Analysing consumer adoption of cashless payment in Malaysia. Digital Business, 1, (2020).

Sinha, A., Gupta, K., Singh, R. K., \& Jamshed, A. (2020). Trash management for smart cities An intelligent approach for garbage collection. International Conference on Innovative Computing and Communication.

United Nations. (2018a). Department of Economic and Social Affairs. In World Urbanization Prospects - The 2018 Revision (ST/ESA/SER.A/420); United Nations: New York; Available online: https://population.un.org/wup [Accessed on 24 May 2021]

United Nations. (2018b). Department of Economic and Social Affairs. Malaysia Percentage of Population in Urban and Rural Areas; United Nations: New York; Available online: https://population.un.org/wup/Country-Profiles/ [Accessed on 23 May 2021 